\title{
The Delphi Method for Internationalization of Higher Education in Pakistan: Integrating Theory of Constraints and Quality Function Deployment
}

\author{
Muhammad Imran Qureshi \\ Faculty of Management, Universiti Teknologi Malaysia, \\ 81310 UTM Skudai, Malaysia. \\ Mansoor Nazir Bhatti \\ Faculty of Management, Universiti Teknologi Malaysia, \\ 81310 UTM Skudai, Malaysia.

\section{Amran Md Rasli (corresponding author)} \\ Faculty of Management, Universiti Teknologi Malaysia, \\ 81310 UTM Skudai, Malaysia. \\ Email:m-amran@utm.my
}

Muhammad Yasir

Faculty of Management, Universiti Teknologi Malaysia, 81310 UTM Skudai, Malaysia.

Khalid Zaman

Department of Management Sciences, COMSATS Institute of Information Technology, Abbottabad, Pakistan.

\section{Doi:10.5901/mjss.2014.v5n20p2702}

\section{Abstract}

\begin{abstract}
Improvement of workforce quality is a major concern for the developing countries like Pakistan. Country's higher education standard determines the quality of their workforce. Developing countries are continuously experiencing different methodologies for the improvement in the higher education standards and to meet the international standards. This study provides a roadmap for improvements in the higher education quality to meet international standard. The study used Delphi approach for the processes of internationalization of higher education. A Delphi panel of 20 educationists participated in the study having minimum 15 years of experience and 3 years in any international institution of higher education. A road map for the internationalization of higher education in Pakistan has been developed from the outcomes of the Delphi panel. In addition, this study used Quality Function Deployment (QFD) as a tool for analyzing the relationship between quality factors of higher education and technical constraints of the higher education institutions. The results show that managerial support and commitment is a key to success in the internationalization of higher education.
\end{abstract}

Keywords: Higher Education; Internationalization; Quality Function Deployment; Delphi Method; Pakistan.

\section{Introduction}

The country's work force quality could be measured by the standard of higher education of the country. Much attention has been given to the improvements in higher education recent decade. Emergence of the new fields of study in the higher education in the different countries leads to the challenges of globalization of higher education. Scot (2000) concludes that the challenges facing higher education in the new millennium cannot be understood unless proper account is taken of the phenomenon of globalization. Scot further emphasized that globalization cannot simply be seen as a higher form of internationalization; it is a much more turbulent phenomenon that not only transcends but ignores national boundaries. Globalization is one element within a larger shift from modernity to post-modernity, which involves not only 
the radical reconfiguration of society but also an even more radical reconstitution of the concepts and mentalities of the modern world. The university is caught in the middle - as both an institution that embodies modernity but also one of the instrument that is most actively transcending its limits.

The 1990s mark an important phase in the evolution of the internationalization of higher education. One distinguishing feature is the different priorities the various stakeholder groups ring to the international dimension of higher education. A number of overreaching issues emerged as important themes to consider, including: international education standards; preparation of globally knowledgeable \& intercultural competent graduates; recruiting and supporting international student; teaching of foreign languages and curriculum reform. The strengths of universities reside increasingly in maintaining effective relationships with their environment, offering answers to the needs of all its stakeholders, placing them in the center of the academic and researcher processes (Cancela et al. 1997).

Basic parameters of globalization process are to improve quality standards of the higher education. Quality refers to the conformance of the customers' requirements (Crosby, 1979). Ishikawa (1990) argued that "quality management is characterized by the strategic goals that are focused towards customer's preferences".

According to Qureshi et al. (2012), quality of higher education is its ability to produce a steady flow of people with high intelligence and commitment to learning that will continue the process of transmission and advancement of knowledge. Global Market needs reconfiguration of quality standard of universities according to the international standard for the process of internationalization of higher education. A system thinking approach is required for the improvements in higher education for internationalization purpose so a universal set of skills could be provide to the labor market to improve the workforce quality and to meet the challenges of globalization. One approach of system thinking and redesigning is named theory of constraints which leads to identify the system constraints and provide logical thinking mechanism to exploit these constraints. Current study will use Delphi approach for the system thinking and improvement of quality education by providing a roadmap for the process of internationalization and investigate the relationship of the improvements parameters with constraints by using QFD.

\subsection{Internationalization of Higher Education}

Higher education has become an integral part of globalization process. Internationalization of higher education is matter of great concern for the higher education institutions during last decade. Universities and higher education institutions are focusing to be considered international. This intentional shift caused by changes in the global market. As the twenty-first century begins to unfold; internationalization of the university has become a strategic high priority for numerous universities across world, During the last decades universities worldwide have come under increasing pressures to adapt to rapidly changing social, technological, economic and political forces emanating from the immediate as well as from the broader postindustrial external environment. The unprecedented growth, complexity and competitiveness of the global economy with its attendant socio-political and technological forces have been creating relentless and cumulative pressures on higher education institutions to respond to the changing environment requiring far-reaching institutional adaptations (Bartell, 2003).

Another aspect of the need for internationalization of higher education is academic and professional requirements of the students. According to Qiang (2003), academic and professional requirements for the graduates increasingly reflects the demands of the globalization of the societies, economy and labor market, thus higher education must provide an adequate preparation for that, these requirements includes not only academic and professional knowledge, but also multilingualism, social and intra cultural skills and attitudes.

This statement reflects the nature and requirements of internationalization of the higher education to provide a universal set of skills to students. As student mobility has great influence on the process of the internationalization. Harris (2008) argued that, the words 'international' and 'internationalization' are frequently used today in association with the university in a number of ways. For example, with the rise in numbers of international students attracted to study in UK universities, it is increasingly common to hear the term 'international' used as a more politically correct term for 'overseas', with its colonial and imperialist associations, to distinguish' home students' from those who are not 'home students'. It is also used in relation to the importance attached to the international reputation of an institution a measure of excellence, and in relation to the impact of globalization and the emergence of the 'international citizen' or 'global citizen'. Queshi et al. (2013) provided parameters for the improvements for the international status of higher education institutions in Pakistan. There are eight basic dimensions in which successful higher education internationalization could be measured. Each dimension has some measure for the improvements.

i) MoU: Number of MoUs with the international universities.

ii) Strategic plan: Top leadership and dispersed leadership support the goal of internationalization. 
iii) Vision / Mission: A vision and mission statement exists that identifies internationalization as a core value, principle and goal of the university

iv) Multi-culturisim: Number of co-curricular activities (e.g., student internships, clubs, service learning, etc.).; Number of international students and Number of international faculty

v) Collaboration /Partnership: Number and percentage of faculty members that have participated in a particular international partnership; Number of programs in collaboration with international universities and Number of student exchange

vi) Knowledge / Skills: Number and percentage of faculty who actively support the goal of comprehensive internationalization; Number and percentage of students and faculty studying and teaching abroad; Number and percentage of faculty taking advantage of development opportunities related to global research, teaching and service etc.

vii) Global Courses :Number and percentage of courses and course components that can be characterized as global

viii) Global Expansion: The administrative structure reflects the internationalization goal; Number of internal Campuses; Number of International liaison offices etc. Universities must have to measure their progress according to the above indicators of each dimension in order to internationalization of the higher education in Pakistan.

\subsection{Higher Education Quality}

In 1970s, quality function deployment (QFD) started in Japan, but it was not until the 1980s that the Western world began to appreciate it as a technique and began using it as a tool for decision-making purposes. QFD has been applied successfully in many Japanese organizations to improve processes and to build competitive advantage. Today, companies are successfully using QFD as a powerful tool that addresses strategic and operational decisions in businesses. "QFD provides a means of translating customer requirements into appropriate technical requirements for each stage of product development and production (i.e., marketing strategies, planning, product design and engineering, prototype evaluation, production process development, production, sales)" (Sullivan, 1986). In 1986, Kelsey Hayes used QFD for developing a coolant sensor that fulfilled critical customer needs such as "easy-to-add coolant", "easy-to-identify unit", and "provide cap removal instructions" (King, 1987; Prasad, 1998).

The above discussion confirms the strong correlation between higher education quality and $\mathrm{i}$ internationalization of universities' reforms in the developed and developing countries. This study used Delphi approach for the process formulation of internationalization of higher education in Pakistan.

\section{Literature Review}

The review of the literature indicates that the early adopters of QFD in the USA were large companies such as AT\&T, Baxter Healthcare, Budd, Chrysler, DEC, Ford Motor Company, General Motors, Goodyear, Hewlett-Packard, IBM, ITT, Kodak Eastman, Motorola, NASA, NCR, Polaroid, Procter and Gamble, and Xerox (Adiano and Roth, 1994; Bosserman, 1992; Cohen, 1995; Dika, 1995; Griffin, 1992; Hauser and Clausing, 1988; Kim et al., 1997; Morrell, 1987; Prasad, 1998; Schaal and Slabey, 1991; Sharkey, 1991; Shipley, 1992). Many companies exist worldwide today that have taken QFD technology into consideration to provide products that are marketable and tasteful to their customers, and build able by their production expert teams (Griffin and Hauser, 1992; Chan and Wu, 2002).

Researchers such as Sullivan (1986), Hauser and Clausing (1988), Zairi and Youssef (1995), Chan and Wu (2002), and Terninko (1995) have discussed on the benefits of QFD. These benefits, as pointed out by researchers in the literature, can be summarized as follows. QFD can help in making trade-offs between what the customer demands and what the company can afford to produce; enhance teamwork among engineers in departments; increase customer satisfaction (this is done by taking customers' requirements into consideration and bringing them into the product development process); shorten the time to market; cause employees to provide sufficient documentation because they see the importance of information; and. improve effective communication between company divisions.

\subsection{System Thinking: Theory of Constraints}

A new approach to the management of production and operations was developed by Goldratt in the late 1970s. Now known as the theory of constraints (TOC), it provides a coherent management theory for running an organization. It has 
two major components: a philosophy which underpins the working principle of on-going improvement, and a generic approach for investigating, analyzing and creating solutions to problems called the "thinking process" (TP). During the last decade several books and many articles have been published, and a journal has been established which deals solely with the TOC. This paper contains an analysis of a comprehensive list of publications on the TOC. Identified themes are classified as conceptual explanation and enhancement of the approach, comparison with other techniques based on its philosophy, and applications in areas such as production, purchasing, accounting, administration, education and quality management (Rahman, 1998).

In 2004, the Theory of Constraints celebrated its Silver Anniversary. In twenty-five years, what started out as a scheduling software has evolved into a management philosophy with practices and principles spanning a multitude of operations management sub disciplines. As the Theory of Constraints has grown, so has its acceptance by both practitioners and academicians. At this point in its development, as it transitions from niche to mainstream, it is important to review what has been accomplished and what deficiencies remain so that both the promise and problems impeding greater acceptance can be examined. To that end, we review the evolution of principal TOC concepts and practices in an objective fashion (Watson et al. 2007).

The theory of constraints (TOC) is a multi-faceted systems methodology that has been developed to assist people and organizations to think about their problems, develop breakthrough solutions and implement those solutions successfully. This paper describes a literature-based research project examining the results of TOC applications reported in the literature. In particular, it presents here the results of a meta-analysis of over 80 successful TOC applications, based on available quantitative data, which showed that significant improvements in both operational and financial performance were achieved as a result of applying TOC. Despite extensive searches, the research found no reports of failures. While reports are mainly from manufacturing organizations, the findings may be general sable to other types of organizations, particularly to their operational aspects. The paper concludes with an agenda for future research on the use of TOC in operations and production management (Mabin and Balderstone, 2003).

\section{Methodology}

The current study used Delphi method for the collection of feedback and to determine the road map for the internationalization of higher education in Pakistan. The Delphi method is a popular technique for forecasting and an aid in decision-making based on the opinions of experts, which has been in existence for over half a century. This work evaluates its methodology and reviews its validity in the present day, especially in the area of Social Sciences. Three recent applications in this field are also explained, professional in nature, which have some characteristics that are not frequent with respect to other Delphi studies published. The main aim of two of these studies was to provide input for economic or statistical quantitative models, using the judgment of expert groups, while the third study aimed to analyze a complex social reality by means of a Policy Delphi in order to obtain reliable information before taking a policy decision. These applications highlight how this technique may be adapted to different social realities and requirements, making a positive contribution to social progress, provided it is applied with the necessary methodological rigors and with a good knowledge of the social medium in which it is being applied. Finally, there is an explanation of a number of lessons learned from the theory and aforementioned experiences, which may contribute to the successful outcome of a Delphi exercise (Jonlandeta, 2006). The Delphi method is a structured communication technique, originally developed as a systematic, interactive forecasting method which relies on a panel of experts (Dalkey and Helmer, 1963); Brown, 1968; Sackman, 1974; Linstone and Turoff, 1975).

The experts answer questionnaires in two or more rounds. After each round, a facilitator provides an anonymous summary of the experts' forecasts from the previous round as well as the reasons they provided for their judgments. Thus, experts are encouraged to revise their earlier answers in light of the replies of other members of their panel. It is believed that during this process the range of the answers will decrease and the group will converge towards the "correct" answer" (Rowe and Wright, 1999). Delphi is based on the principle that forecasts (or decisions) from a structured group of individuals are more accurate than those from unstructured groups (Rowe and Wright, 2001). The technique can also be adapted for use in face-to-face meetings, and is then called mini-Delphi or Estimate-Talk-Estimate (ETE). Delphi has been widely used for business forecasting and has certain advantages over another structured forecasting approach, prediction markets" (Green et al.2007). The Delphi method has proven a popular tool in social sciences research for identifying and prioritizing issues for managerial decision-making (Okoli and Pawlowski, 2004). The Delphi method is one of the effective methods which enable forecasting by converging a possibility value through the feedback mechanism of the results of questionnaires, based on experts' judgments (Ishikawa et al. 1993).

This study used Delphi approach for the collection of data from the experts in the field of education for analytic 
arguments for the internationalization of the Higher education in Pakistan. The sample consist of 20 subject experts having minimum 15 years of experience in the field of education and worked at least 3 years in any international university. Constitution of the said criteria is to ensure the validity of the received opinions. An open ended questionnaire was distributed to these experts for their expert opinions focusing on the major factors related to the internationalization process (Qureshi, et al. 2013) and discussed in the previous section (i.e MoUs, Strategic planning, Vision, Multiculturalism, Collaboration with international universities, Knowledge / skills, Global courses and global expansion). Figure 1 shows the research framework of the study.

Figure 1: Research Framework of the Study

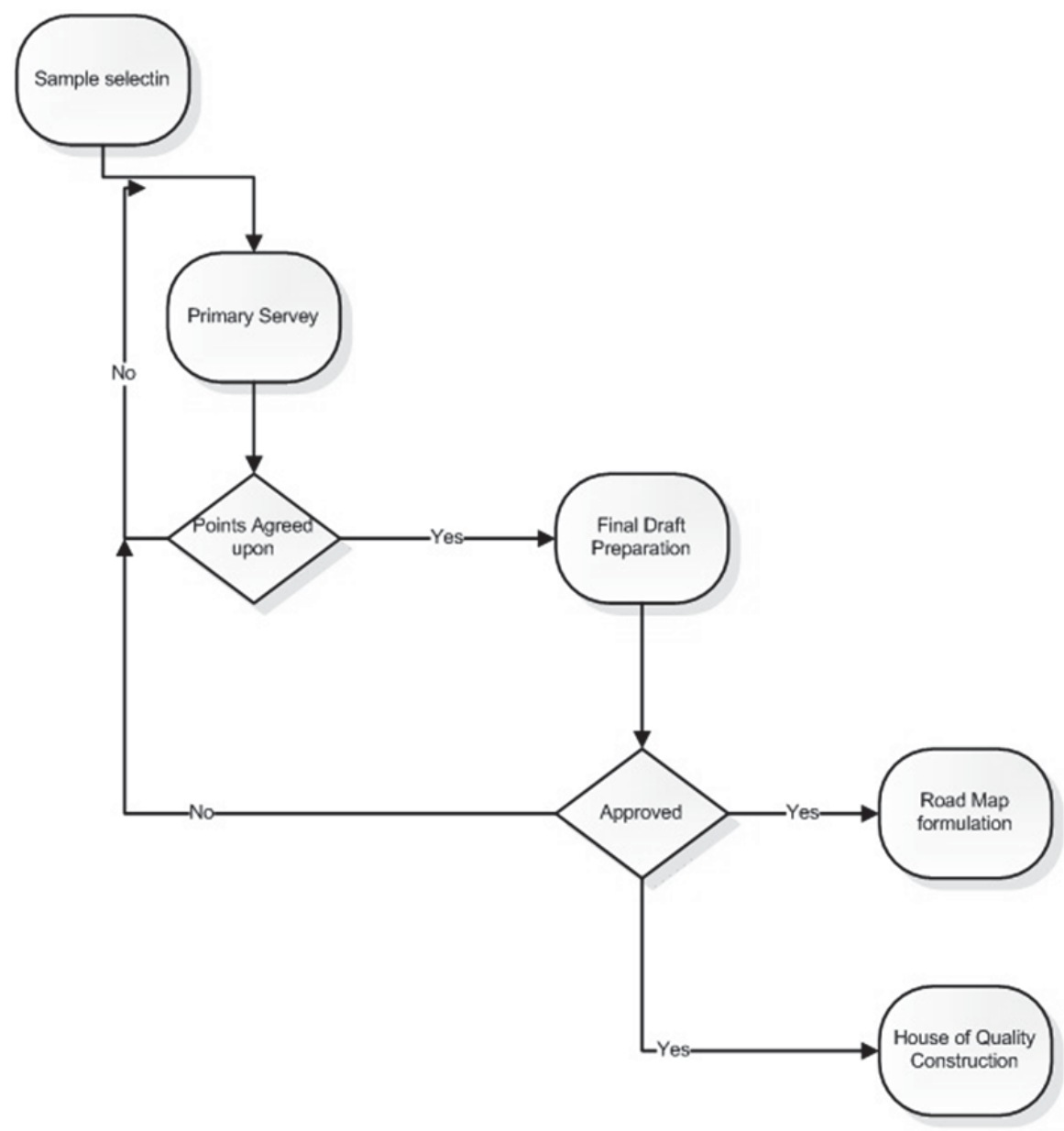

Further response was analyzed for the consensus among these experts and then a final draft was sent to these experts for the final approval. Discussions highlighted in next section are based on the consensus among these experts and a house of quality is built to identify the relationship between constraints and basic parameters of improvement.

\section{Results and Discussion}

The Delhi panel results indicate the consensus among experts and established a road map for the internationalization of higher education in Pakistan. Road map consists of the steps as shown in the Figure 2. 
Figure 2: Road Map for Internalization

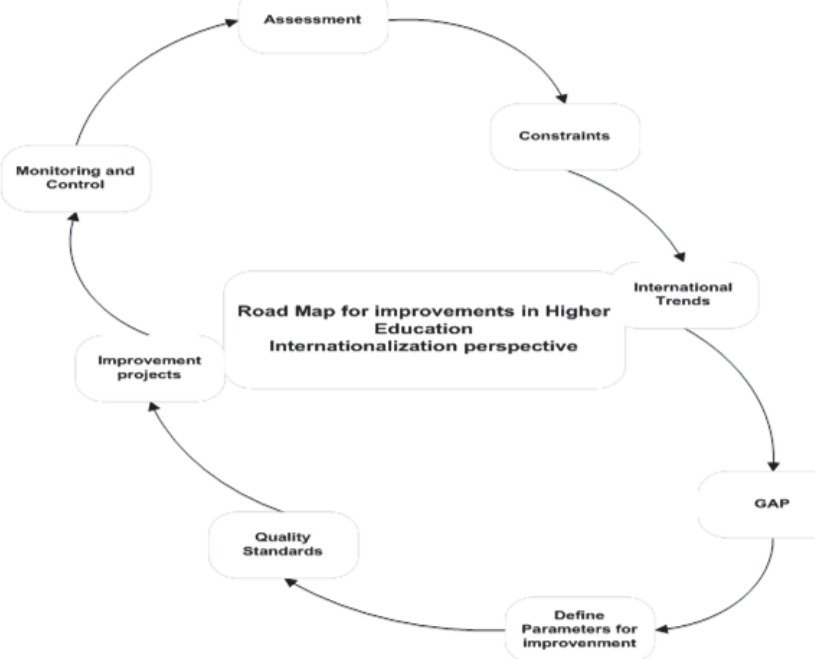

Figure 2 shows an eight step roadmap for the internationalization of the higher education in Pakistan, 'assessment' of the current scenario of the higher education in the Pakistan is a starting point for the continuous improvement process in the higher education Institutions in Pakistan. Higher education institutions intend to internationalize their status they must assess their current situation keeping in mind the influence of internal and external environment. This study focuses on the parameters identified by Qureshi et al (2013). Higher education institutions intended to be internationalized must built a vision for the internationalization and need to formulate strategic plan for this purpose. To start with strategic planning institutions must assess their current situation. After the assessment of their current situation higher education institutions must identify their 'constraints'. Every organization have several constrains. Institutions have to identify them and find ways to exploit them. Constraints could be financial, structural, procedural, technological, economic or political and managerial support. Approach discussed in the previous section name Theory of Constraints provides logical thinking to exploit process constraints. Analysis of 'International trends' is mandatory to find out 'Gap' between local and international trends. Analysis provides basic 'parameters for the improvements' and to determine required 'quality standards' and 'improvements projects' could be employed but there must be 'monitoring and control' for the continuous improvement process. In addition, this study suggested the use of house of Quality i.e., a Quality function Deployment technique which emphasis getting customer vice in design process, to understanding the relationship between Parameters of internationalization and constraints.

\subsection{House of Quality}

Delphi technique results were employed to build a house of quality to understand how internationalization of higher education in Pakistan could be possible, and what are the difficulties higher education institution are facing in Pakistan during the internationalization process. QFD is one of the important tool of total quality management (TQM), which is most often used for process and design improvement (Aytac and Deniz, 2005; Hwarng and Teo, 2001; Singh et al., 2008). The main purpose of QFD is to visualize the cause-and-effect relationships taking a start from the customer needs and then all the way down till the production process. QFD is a structured approach to find out the customer requirements, specified with products and service design. The benefits of design are focused on customer requirements, prioritizing design activities and it also reduces the design cycle.

QFD is referred as a process which includes (a) identifying and ranking the relative importance (1 for least important and 10 for most important) of customer requirements; (b) identifying design parameters (or engineering characteristics) that contribute to the customer requirements; (c) estimating the relationship ( weak ranked 1 moderate ranked 3 and strong ranked 9) between design parameters and customer requirements and among different design parameters, and (d) setting target values for the design parameters to best satisfy customer requirements. A QFD matrix which is also called house of quality is used to help the decision makers to make the design decisions and predict the 
right one. QFD has been successfully used for both product and service design by many organizations (Cohen, 1988; Hauser and Clausing, 1988; Pitman et al., 1995).

The study used House of quality to determine the relationship of the customer requirements with the organizations difficulties to fulfill these requirements. Basic requirements for the internationalization of the higher education are already determined in the literature section. Organizational constraints are determined by the Delphi approach. There are six constraints were determined which has strong relationship with the requirements for the internationalization of higher education. These constraints are managerial support, financial constraints, structural constraints, procedural constraints, quality constraints, technical constraints and economical and political constraints. Figure 3 shows the quality function deployment by using house of quality.

Maximum relationship column indicate the row maximum relationship with the technical descriptors and customers requirements. Customer's importance for the each requirement is given in the adjacent column and relative weight indicates the relative importance of each factor. Technical importance rating indicates the importance of each constraint with reference to the customer's requirements, higher the value important the constraint is for internationalization of higher education process. Wight chart indicates the relative importance of the constraint among others. Quality function deployment revealed the most important factor which contributing in improvements of almost all parameters is Management support having importance rating 780 and $32 \%$ relative weight. All experts are agreed upon primary role of top management support in the internationalization of higher education in Pakistan. Financial constraints are also important for the internationalization process. Higher education institutions should extend their financial resources in order to achieve internationalization status.

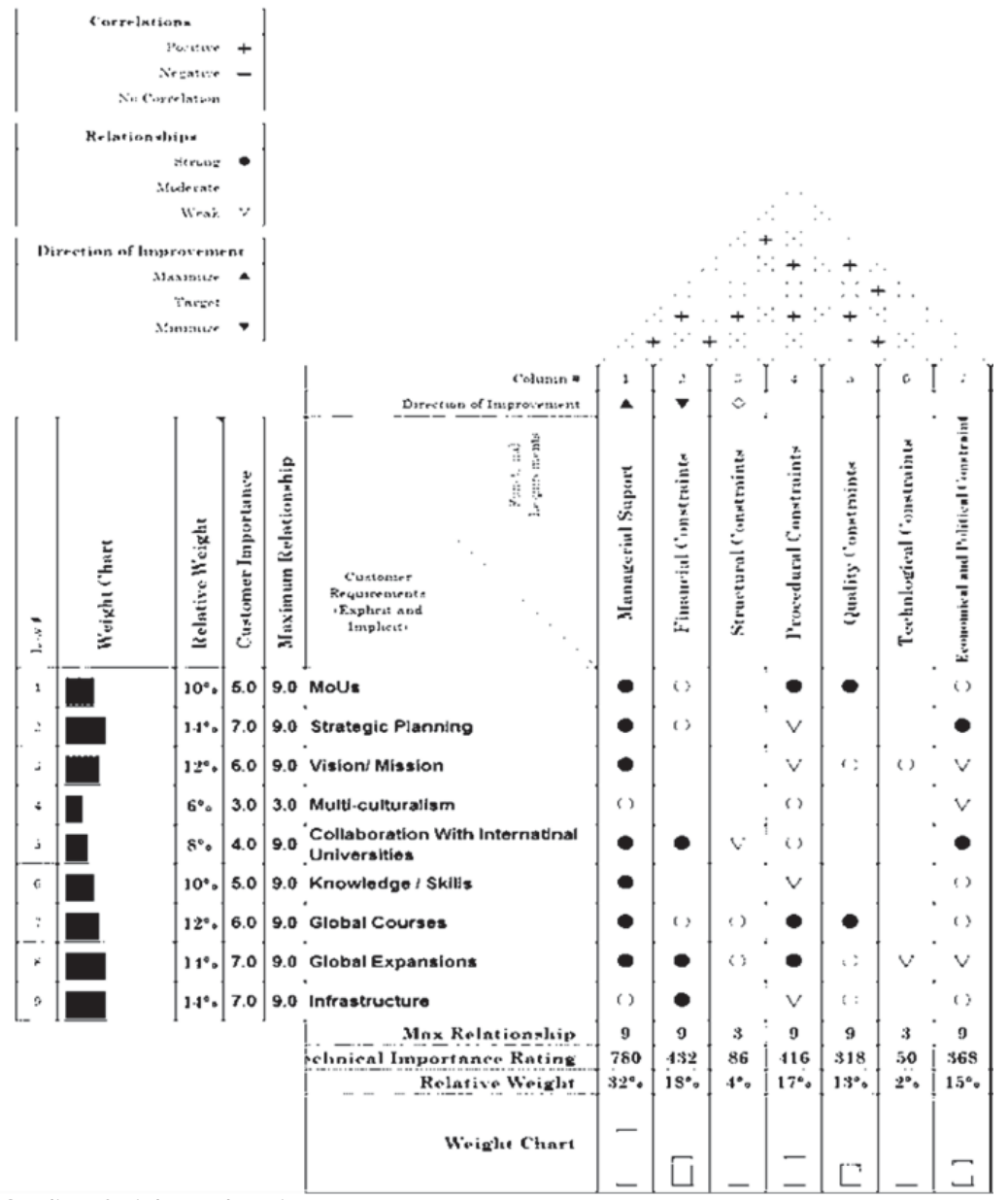

Figure 3: House of Quality of Higher Education 


\section{Conclusion}

Higher education institutions have to find out parameters in order to employee a continuous improvement process to achieve international standards. This study employed Delphi technique of qualitative research to determine the roadmap through which internationalization of higher education in Pakistan could be possible. Study confides an eight step roadmap for the internationalization of higher education in Pakistan. A detail assessment of the current Higher Education status in the Pakistan would be the starting point for the processes of internationalization of higher education in Pakistan. A gap has to be found in order to overcome these gaps for the internationalization purpose and raising the quality standard and define a mechanism for the monitoring and control for the up gradation of higher education process.

Theory of Constraints focuses that every organization has different constraints and different methodologies to exploit these constraints. The study provides house of quality which is useful for the higher education institutions to understand difficulties to improvements of the parameters related to internationalization of higher education in Pakistan and their relationship with the organizational constraints. Study also highlighted important factors that contribute in the process of internationalization, most important factor is managerial support or top management commitment towards internationalization of higher education process.

Study is useful for the higher education institutions to understand the process of internationalization of higher education in the Pakistan to understand the steps required by the higher education institutions in the Pakistan for the purpose of internationalization of higher education, study of their constraints.

\section{References}

Adiano, C., \& Roth, A. V. (1994). Beyond the house of quality: dynamic QFD. Benchmarking for Quality Management \& Technology, $1(1), 25-37$

Bartell, M. (2003). Internationalization of universities: A university culture-based Framework Higher Education 45: 43-70.

Bosserman, S. (1992). Quality function deployment: the competitive advantage. Private Trunked Systems Division, Motorola.

Brown, B. B. (1968). Delphi process: A methodology used for the elicitation of opinions of experts (No. RAND-P-3925). RAND CORP SANTA MONICA CA.

Cancela, A., Sanchez, A., Gandon, R., Rey, M. J., \& Carrera, E. (2010). Quality assurance in higher education. Journal of studies in international education, 1, 127-44

Chen, L. H., \& Weng, M. C. (2006). An evaluation approach to engineering design in QFD processes using fuzzy goal programming models. European Journal of Operational Research, 172(1), 230-248.

Chen, L.-H., and Weng, M.C. (2003). A fuzzy model for exploiting quality function deployment. Mathematical and Computer Modeling, 38, 559-70.

Chin, K. S., Wang, Y. M., Yang, J. B., \& Gary Poon, K. K. (2009). An evidential reasoning based approach for quality function deployment under uncertainty. Expert Systems with Applications, 36(3), 5684-5694.

Cohen, L. (1995). Quality Function Deployment: How to Make QFD Work for You, Addison-Wesley, Reading, MA.

Crosby, P. B. (1979). Quality is Free: The Art of Making Quality Certain. New York: McGraw-Hill.

Dalkey, N., \& Helmer, O. (1963). An experimental application of the Delphi method to the use of experts. Management science, 9(3), 458-467.

Deming, W. E. (1988). Out of the Crisis: Quality, Productivity, and Competitive Position. New York: Cambridge University.

Dika, R.J. (1995). QFD implementation at Chrysler: the first seven years, in Eureka, W.E. and manufacturing - a comparison between two new product teams, Management Science, 38(3), 360-373.

Green, K. C., Armstrong, J. S., \& Graefe, A. (2007). Methods to elicit forecasts from groups: Delphi and prediction markets compared. Foresight. The International Journal of Applied Forecasting, 8(8), 17-21.

Griffin, A. (1992). Evaluating QFD use in US firms as a process for developing products. Journal of Product Innovation Management, 9(3), 171-87.

Griffin, A. \& Hauser, J.R. (1992). Patterns of communications among marketing, engineering Harold A. Linstone, Murray Turoff (1975), The Delphi Method: Techniques and Applications, Reading, Mass.: Addison-Wesley, ISBN 978-0-201-04294-8.

Harris, S. (2008). Internationalising the University. Educational Philosophy and Theory, 40(2), 121-129.

Hauser, J.R. \& Clausing, D. (1988). The house of quality. Harvard Business Review, 66, 63-73.

Housel, T., \& Kanevsky, V.A. (1995). Reengineering business processes: a complexity theory approach to value added. INFOR, 33(4), $248-62$.

Hrones, J.A. Jr, Jedrey, B.C. Jr \& Zaaf, D. (1993). Defining global requirements with distributed QFD. Digital Technical Journal, 5(4), 3646.

Ishikawa, A., Amagasa, M., Shiga, T., Tomizawa, G., Tatsuta, R., \& Mieno, H. (1993). The max-min Delphi method and fuzzy Delphi method via fuzzy integration. Fuzzy sets and systems, 55(3), 241-253.

Kim, K.J., Moskowitz, H. \& Shin, J.S. (1997). Design decomposition in quality function deployment, in Karwan, M.H., Spronk, J. and Wallenius, J. (Eds), Essays in Decision Making, Springer-Verlag, Berlin, pp. 215-36. 
Kim, K. J., Moskowitz, H., Dhingra, A., \& Evans, G. (2000). Fuzzy multi-criteria models for quality function deployment. European Journal of Operational Research, 121, 504-18.

King, B. (1987). Listening to the voice of the customer: using the quality function deployment system. National Productivity Review, 6(3), 277-81.

Knight, J. (1997). A shared vision? Stakeholders' perspectives on the internationalization of higher education in Canada. Journal of Studies in International Education, 1(1), 27-44.

Landeta, J. (2006). Current validity of the Delphi method in social sciences. Technological forecasting and social change, 73(5), 467482.

Mabin, V. J., \& Balderstone, S. J. (2003). The performance of the theory of constraints methodology: analysis and discussion of successful TOC applications. International Journal of Operations \& Production Management, 23(6), 568-595.

Okoli, C., \& Pawlowski, S. D. (2004). The Delphi method as a research tool: an example, design considerations and applications. Information \& Management, 42(1), 15-29.

Prasad, B. (1998). Review of QFD and related deployment techniques. Journal of Manufacturing Systems, 17(3), 221-34.

Qiang, Z. (2003). Internationalization of higher education: towards a conceptual framework. Policy Futures in Education, 1(2), $248-270$.

Qureshi M I, Khan K, Bhatti M N, Khan A \& Zaman K (2012). Quality Function Deployment in Higher Education Institutes of Pakistan. Middle-East Journal of Scientific Research 12 (8), 1111-1118.

Rahman, S. U. (1998). Theory of constraints: a review of the philosophy and its applications. International Journal of Operations \& Production Management, 18(4), 336-355.

Rowe, G., \& Wright, G. (1999). The Delphi technique as a forecasting tool: issues and analysis. International journal of forecasting, 15(4), 353-375.

Rowe, G., \& Wright, G. (2001): Expert Opinions in Forecasting. Role of the Delphi Technique. In: Armstrong (Ed.): Principles of Forecasting: A Handbook of Researchers and Practitioners, Boston: Kluwer Academic Publishers.

Ryan, N.E. (Eds), Quality up, Costs down: A Manager Guide to Taguchi Methods and QFD, ASI Press, Dearborn, MI, pp. 123-63.

Sackman, H. (1974). Delphi assessment: Expert opinion, forecasting, and group process (No. RAND-R-1283-PR). RAND CORP SANTA MONICA CA.

Schaal, H. \& Slabey, W. (1991). Implementing QFD at the Ford Motor Company, Ford Motor

Sullivan, L.P. (1986), "Quality function deployment", Quality Progress, 19(6), 39-50.

Watson, K. J., Blackstone, J. H., \& Gardiner, S. C. (2007). The evolution of a management philosophy: The theory of constraints. Journal of Operations Management, 25(2), 387-402.

Zairi, M. \& Youssef, M.A. (1995). Quality function deployment - a main pillar for successful total quality management and product development. International Journal of Quality \& Reliability Management, 12(6), 9-23. 